\title{
WRITING FOR CHANGE: THE CASE FOR NARRATIVE PERSUASION TECHNIQUES
}

\author{
Kaylia Payne | Southern Cross University
}

\begin{abstract}
Narrative persuasion refers to the process by which people alter their attitudes and beliefs to match that of information provided in a narrative. Studies on the narrative tools contributing to attitude and belief change in the reader have produced results that provide direction for writers seeking to influence and inform the public. In this paper, I explore the narrative persuasion techniques used in two examples of Australian contemporary young adult texts designed to foster empathy for a marginalised group. These fictional works include Boy Overboard (Gleitzman 2002) and The Bone Sparrow (Fraillon 2016), both of which criticise Australia's treatment of asylum seekers. The results of this research have informed the creative work for my PhD thesis, Boundless Plains, which focuses on the issue of Australia's treatment of refugees and asylum seekers, with an emphasis on boat arrivals.
\end{abstract}

BIOGRAPHICAL NOTE

Kaylia Payne is a writer and editor. Her short stories have been published in Tincture Journal and the annual anthology fourW, and she was the winner of the My Grief Assist Award for her piece in the 2017 Grieve print anthology. Kaylia is currently undertaking a $\mathrm{PhD}$ in creative writing at Southern Cross University, where she is working on a novel about Australia's treatment of people seeking asylum.

KEY WORDS

Narrative persuasion-Transportation-Asylum seekers-Identification-Empathy 
The language of border protection is loaded with disinformation and deceit. Illegals. Queue-jumpers. Economic refugees. These are just a handful of the names given to those seeking asylum in Australia, particularly those who arrived, or attempted to arrive, by boat.

The titles given to those seeking asylum almost always have negative connotations and thus contribute to prejudice and negative attitudes towards refugees and asylum seekers. For example, 'illegals' is used as a way to express that those seeking asylum have no legal right to come to Australia and are therefore untrustworthy due to their criminal activity (Croston and Pedersen 2013). This belief, despite its persistence, is inaccurate, as people have a right to seek asylum under the United Nations Convention (1951) and Protocol (1967) Relating to the Status of Refugees, both of which Australia is signatory to. The term 'queue-jumpers' implies unfairness-that those coming to Australia by boat are disadvantaging others who are waiting patiently in line-and leads to negative attitudes towards asylum seekers who are seen as trying to get ahead at the expense of more deserving recipients of Australia's kindness. Lastly, the term 'economic refugee' implies that there are categories of refugees: those who are genuine and deserve our help, and those who are trying to rort the system and gain economic advantage. This again conjures up notions of unfairness and untrustworthiness.

These types of labels, used to vilify asylum seekers and refugees, have played a role in the Australian public's perception of those trying to seek asylum (Martin 2015). According to the Scanlon Foundation: Mapping Social Cohesion Report 2016 (Markus 2016), 61.2\% of respondents either somewhat or strongly disapproved of asylum seekers who tried to reach Australia by boat.

It is clear that a negative narrative regarding a subset of the population is an effective tool for justifying human rights abuses towards them. This leads to the question: can positive narratives about marginalised groups help to undo this damage? Drawing on research around narrative persuasion, this paper will explore narrative persuasion techniques used in two examples of young adult (YA) fiction designed to foster empathy for people seeking asylum in Australia, as well as my own story, Boundless Plains. 
Narrative persuasion

Empirical research (Strange and Leung 1999; Wheeler, Green and Brock 1999; Green and Brock 2000; Busselle and Bilandzic 2009; and Appel and Malečkar 2012) has demonstrated that narratives, including fictional narratives, can influence the beliefs of the reader.

Green and Brock (2000) believe that transportation plays a role in the persuasive effects of textual narratives. Transportation in this instance is a distinct mental process, whereby the reader becomes immersed in the story and narrative world created through an 'integrative melding of attention, imagery, and feelings' (Green and Brock 2000: 701). Transportation leads to a complete focus on the story and causes the reader to lose or turn off access to real-life facts that may contradict the text and the ideas presented within it. Due to this, when the reader emerges from the story their attitudes and beliefs will be changed to reflect what they have learned in the narrative. The notion of transportation has also been influenced by that of identification, suggesting that 'factors making it easier to identify with or understand a character can encourage transportation' (Green 2004: 261).

Busselle and Bilandzic expanded on this in 2009, creating a scale that measures four dimensions of narrative engagement, including narrative understanding, attentional focus, emotional engagement and narrative presence. Of these, only narrative understanding (a lack of difficulty in following the narrative) did not correlate with story-consistent attitudes, though it did contribute to the reader's enjoyment of the narrative. Busselle and Bilandzic (2009) also found that the reader's identification with the characters was correlated with emotional engagement, as this identification led to the reader experiencing either empathy with or sympathy for the characters.

One narrative tool that has been demonstrated to lead to identification is having a protagonist who is similar to the reader. In 2014, de Graaf found that similarities between the reader and the protagonist increased narrative persuasion, as the reader was more likely to relate the lessons learned in the story to themselves and their own life through self-referencing.

Strange and Leung (1999) theorise that an important aspect of narrative persuasion is causal generalisation, which is 'a largely bottom-up process, in which exposure to a person-in-situation instance increases the accessibility of scenario-congruent knowledge' (Strange and Leung 1999: 437). Their study found that narratives influenced the reader's casual judgements about the social 
category to which the protagonist of the narrative belonged. Further to this, their research demonstrated that individual accounts about concrete situations influenced the reader's judgments about society, particularly their belief around the causes of and solutions to social problems. When the focus of the texts was on the individual's own failings, then the reader attributed the social problems to the individual, but when the focus of the texts was on how failings in society had impacted the individual, the reader was more likely to blame society at large for the social problem in question.

Lastly, authors can actively seek changes in belief through 'broadcast strategic empathy', a theory developed by Suzanne Keen (2006). This is when the author emphasises common human vulnerabilities and hopes, in order to encourage the reader to feel empathy for a particular subset of the population.

Emotional engagement, identification, focusing on an individual who is victim to societal failings, and broadcast strategic empathy are important narrative persuasion techniques that have been utilised in Australian contemporary YA fiction to promote empathy for asylum seekers and refugees, as I will discuss below.

\section{Narrative persuasion in action}

Australian writers have not been silent on the subject of Australia's treatment of refugees. There have been numerous nonfiction books written by academics, activists and those of a refugee background, including The Undesirables (Isaacs 2014), What is a Refugee? (Maley 2016), and They Cannot Take the Sky (Green and Dao (eds), Neville, Affleck and Merope (associate eds) 2017).

Australian YA writers have also contributed to a body of work that challenges Australia's policies and the negative stereotypes of asylum seekers and refugees. Two of these texts in particular embody narrative persuasion in action: Boy Overboard by Morris Gleitzman (2002) and The Bone Sparrow by Zana Fraillon (2016). I have chosen to explore these texts as both are written for Australian young adult readers, both have a protagonist who is seeking asylum in Australia, and both encourage empathy for asylum seekers and refugees.

The target reader for these texts (school-aged Australians) is particularly important in this case, as without them the reader may not have exposure to Australia's treatment of asylum seekers and refugees, especially not from the perspective of a person seeking asylum. Narrative persuasion techniques are 
particularly useful in this case, as they help to mitigate the challenge of how best to engage readers in an issue that might seem to have little immediate impact on their own lives.

As discussed, identification is an important aspect of narrative persuasion, contributing to both transportation and emotional engagement. One way in which to foster identification is by having a protagonist who is similar to the target reader. The Bone Sparrow and Boy Overboard are written for young adults and, as such, are from the perspective of a younger protagonist to make it easier for the intended reader to identify with them. The protagonist in Boy Overboard is Jamal, an eleven-year-old boy from Afghanistan, and the protagonist in The Bone Sparrow is Subhi, a ten-year-old Rohingyan boy who was born in an Australian onshore detention centre. Both Jamal and Subhi are likely to have very different life experiences to that of the target reader. Due to this, it was important for Fraillon and Gleitzman to draw on similarities between the protagonist and target reader in order to maximise the identification that occurred. This was achieved through their exploration of the young adult experience, drawing on commonalities that the intended reader is likely to relate to, including the complexities of sibling relationships.

For example, in The Bone Sparrow Subhi is often taunted or teased by his older sister, Queeny, in a way that many of the young readers would be familiar with. 'Then Queeny comes up and jabs at me with her toe. 'Out of the way, Butt Face." (Fraillon 2016: 10). However, another common thread in the novel is the love and fierce protection between siblings. A good example of this is when Queeny protects Subhi from one of the guards, Beaver, who often becomes violent.

It's Queeny who saves me. Queeny, who looks as close to a superhero as I've ever seen. She swoops down to my side, her hair flying out behind her, and stands in front of me, my shield from Beaver (Fraillon 2016: 34).

Sibling relationships are also explored in Boy Overboard through Jamal's interactions with his younger sister, Bibi. Though Bibi and Jamal have a less tumultuous relationship than Queeny and Subhi, they still bicker often throughout the novel. One example of this is when Bibi wants to involve herself in football games with Jamal and his friends, despite knowing that it is illegal in Afghanistan for her to do so. "I'm sick of being stuck indoors,' she says. 'I want to play football. Come on, you soft lumps of camel poop, tackle me" (Gleitzman 2002: 4). 
As with Queeny in The Bone Sparrow, Jamal is also fiercely protective of his younger sibling. This is shown in a scene where Jamal risks his life to save Bibi's when she steps on a landmine. Her words to him when he carefully takes her place on the landmine sums up their relationship well. "If I die, I hope you do as well.' Then her eyes fill with tears again and she puts her arms round me. 'Because if I was dead and you weren't, I'd really miss you' (Gleitzman 2002: 20).

Another common thread in the books that fosters identification between the target reader and protagonist is that of parents limiting the information they share with their children, particularly in regard to difficult or traumatic circumstances.

Subhi, for example, is kept in the dark by those around him about much of what is occurring in the detention centre, as they believe he is too young to understand. Due to this, Subhi comes up with imaginative stories about the world around him, including that a sea comes to the centre at night (the Night Sea) to bring him treasures, to both explain his experiences and provide comfort in a distressing environment.

Jamal and Bibi in Boy Overboard are also given insufficient information about their situation. For example, when Jamal is told that his father is picking his mother up from the football stadium, he comes to the conclusion that they are talking to government officials about both himself and Bibi playing football for the national team one day. It is only when he goes into the stadium himself that he learns his mother was sentenced to a public execution and that his father has gone in to save her. On another occasion, when the parents tell Bibi and Jamal that they have to leave the country, Bibi asks whether it will be like a holiday. 'Mum hesitates. Then she gives me and Bibi a brave smile. 'Sort of,' she says' (Gleitzman 2002: 68).

Lastly, the commonalities between the protagonists and the target reader are shown through the characters themselves, who, like many young adults, have grand goals for their future. Jamal, for example, dreams of becoming a famous football player and showing the world that he is worthwhile.

If I can become the star of the Afghanistan national football team, perhaps that'll make all of us more popular, not just me and Mum and Dad and Bibi. Perhaps none of us will ever be threatened or bullied or killed again, not by the government of anybody.

It's a good plan.

A really good plan (Gleitzman 2002: 42). 
Both Fraillon and Gleitzman write about the experience of being a young adult, drawing on commonalities that their intended reader is likely to relate to. These commonalities are then used to highlight the differences between the intended reader and the protagonists. For example, through The Bone Sparrow Fraillon effectively portrays the cruelty inherent in locking people in indefinite detention, not through big, sweeping statements, but through the small, everyday moments that highlight the differences between free children and those whom the Australian government has locked away indefinitely. Take, for example, the childhood activity of measuring oneself after a growth spurt. Subhi, being born in a detention centre, measures himself against the fence that separates him from Outside. "Maá?' I whisper. 'I measured. I'm twenty-one fence diamonds high" (Fraillon 2016: 91).

Fraillon also cleverly contrasts Subhi's experience with that of a young girl he meets, Jimmie, who lives near the detention centre and strikes up a friendship with Subhi. Jimmie and Subhi are similar in regard to their dreams and vulnerabilities, and these similarities make the differences in their quality of life, with one person being free and the other detained, even more pronounced-for example, when Jimmie describes her bedroom to Subhi and he is unable to picture it. 'In my head I'm trying to imagine a room with a dragon poster, but all I can imagine is a container room like the ones in Hard Road' (Fraillon 2016: 96).

Keen's theory of broadcast strategic empathy seems applicable in this case, as by highlighting the similarities between Jimmie and Subhi, as well as between Subhi and the reader, Fraillon fosters empathy for the person locked in indefinite detention.

Both books are also written in the first person, giving the reader greater insight into the protagonist's thoughts and feelings and thus encouraging the reader to experience self-referencing, leading to stronger emotional engagement in the story.

The stories are used to highlight the reasons why people need to seek asylum and, through both the central narrative and the use of other characters seeking asylum who the protagonists meet along the way, these stories demonstrate that the challenges the protagonists face are representative of the marginalised group they belong to. Many myths about asylum seekers include the idea that people who seek asylum are failing in some way-whether it is by seeking asylum the 'wrong' way or not being entitled to seek asylum at all. As research by Strange and Leung (1999) demonstrates, narratives about social issues are more likely to be persuasive if they show that the issue is due to a societal rather than individual 
failing. The Bone Sparrow and Boy Overboard do this by challenging the persistent myths in Australia about asylum seekers, including that they are 'queue-jumpers' and 'economic refugees'.

Gleitzman's book in particular delves into the reasons why someone would need to seek asylum. Over the course of the novel, the reader (through Jamal's eyes) sees his house blown up, his mother captured and nearly executed, and the family having to flee the country in order to save their lives.

Both books also make it clear that the characters are not seeking asylum simply because they do not like their home country, which is another pervasive myth.

‘Where’s Australia?’ says Bibi.

'A long way away,' says Dad, and in his voice I can hear how much he wishes we could stay at home (Gleitzman 2002: 73).

While the term 'queue-jumpers' is often used, there is no orderly queue nor is it 'first-come first-served' process. Further, many people seeking asylum do not have access to a UN office and are thus unable to apply for resettlement. Gleitzman sums this up well during a short scene in which Jamal attempts to talk to UN officials. There is a UN office in the camp, but as there are hundreds of people desperately trying to get to the UN officials and no semblance of order, the UN officials leave without speaking to anyone.

'Come back,' I yell.

It's what everyone else is yelling too.

A few hundred people are running after the car, but they're not catching it (Gleitzman 2002: 86).

Boy Overboard and The Bone Sparrow end with the impact of Australian policy on those seeking asylum, demonstrating to the reader that their suffering is not due to individual failing but rather because they are being used as political tools. For example, Gleitzman's character, Jamal, is told about Australia's refugee policy through an Australian officer named Andrew.

'There was an election in Australia,' he says. 'The Australian government thought they'd get more votes by keeping you out.' His voice goes even quieter and sadder than before. 'And they did' (Gleitzman 2002: 179).

This again ties into the findings by Strange and Leung (1999) that narratives are persuasive when they make clear that the protagonist's suffering is due to a 
c in d e r

societal failing. The Bone Sparrow and Boy Overboard do this well, making them concrete examples of narrative persuasion in action.

\section{Narrative persuasion in Boundless Plains}

I chose to write a YA book after exploring the narrative persuasion techniques in Boy Overboard and The Bone Sparrow. However, my target audience is slightly older (late high school-aged) and, as such, I have employed the use of a protagonist of a similar age.

Boundless Plains begins after the sinking of a boat off the coast of the Cocos Islands, killing forty-one people seeking asylum and twenty-three-year-old Australian journalist, Adrienne Cumberland. The death of Adrienne captures national attention, particularly when it is reported that she was working on a book comprising of interviews with refugees and asylum seekers. Boundless Plains is told from the perspective of the main protagonist, Breanna, who is Adrienne's younger sister. On the day of Adrienne's funeral in Canberra, a leaked email implies that Australian Border Force Officers knew about the sinking ship yet were instructed to ignore it. That same day, Rajan Thiranagama, a Tamil journalist and refugee in the Manus Island detention centre, contacts Breanna. He believes his brother, Suresh, may have been on the same boat as Adrienne. Together, they work to finish Adrienne's book.

As per the research by de Graaf (2014), having a protagonist who is similar to the reader is more likely to lead to narrative persuasion through self-referencing. Breanna, the protagonist, is a character representative of many Australians. Breanna is apolitical and does not have a clear understanding of Australia's current refugee policies. The death of her sister brings something that would otherwise have remained on the periphery of her vision to the forefront, and she learns through others about their experience of seeking asylum in Australia and how Australia's policies impact on their human rights. My goal is to have the target reader-a young Australian citizen with limited understanding of refugee policies-mirror the protagonist's journey in terms of gaining knowledge around Australia's refugee policies and developing empathy for those affected by them. I also chose to use Breanna as the protagonist as it speaks to the fact that the Australian media tends to pay more attention to tragedy when the victims are seen as one of 'us'. This will also be highlighted in the media storm around Adrienne's death, with the names of the other victims on the boat never mentioned by politicians or in the media. Further to this, I also found the contrast between the two characters in The Bone Sparrow, Subhi and Jimmie, to be a 
useful narrative tool and one I have chosen to employ in Boundless Plains. The differences between Breanna's experience and that of Rajan's are highlighted to show the contrast between a life of freedom and one of indefinite detention, drawing on Keen's (2006) broadcast strategic empathy by emphasising their shared humanity. One example of this will be the grief they are both experiencing due to the loss of a sibling. This is also an important tool for emotional engagement, as grief is a universal experience and one that many readers could relate to.

I have also chosen to draw on sibling relationships as a way to highlight the similarities between protagonist and target reader, and to promote selfreferencing. As with the sibling relationships in The Bone Sparrow and Boy Overboard, Breanna is both frustrated by and fiercely protective of her sister, which will be shown through her actions after her sister's death as well as through flashbacks depicting scenes from her and Adrienne's childhood.

Lastly, narratives are more likely to promote positive attitudes towards members of a marginalised group if they demonstrate that their circumstances are not due to individual failing (Strange and Leung 1999) and vice versa. The reasons why Rajan and other characters Breanna meets had to seek asylum are explored throughout the novel and are used to demonstrate that those seeking asylum are not 'illegals', 'queue-jumpers' or 'economic refugees'. Rajan's background and story are explored in detail. Further, a focus of Boundless Plains is on the fact that seeking asylum is an act one is forced to take when facing persecution, not someone's defining characteristic. Rajan-a son, friend, journalist, grieving brother, keen cricketer, Clash of Clans addict and smart-arse-is an example of this in the novel.

\section{Conclusion}

Drawing on narrative persuasion research and using Boy Overboard and The Bone Sparrow as concrete examples of narrative persuasion in action, I have developed Boundless Plains in an attempt to influence the attitudes and beliefs of the reader towards asylum seekers using narrative persuasion techniques. The techniques include fostering emotional engagement, identification, and broadcast strategic empathy. In particular, Boundless Plains challenges the negative narratives used to vilify those seeking asylum by focusing on both the broader societal failings that lead people to seek asylum by boat and Australia's failings in locking them in detention rather than providing assistance. 


\section{Works Cited}

Appel, Markus and Barbara Malečkar 2012 'The Influence of Paratext on Narrative Persuasion: Fact, Fiction, or Fake?' Human Communication Research 38 (4), $459-484$

Busselle, Rick and Helena Bilandzic 2009 'Measuring narrative engagement' Media Psychology 12 (4), $321-347$

Croston, Jared and Anne Pedersen 2013 “Tell me what I want to hear': Motivated recall and attributions in media regarding asylum seekers' Australian Journal of Psychology 65 (2), $124-133$

de Graaf, Anneke 2014 'The effectiveness of adaptation of the protagonist in narrative impact: similarity influences health beliefs through self-referencing' Human Communication Research 40 (1), 73 - 90

Fraillon, Zana 2016 The Bone Sparrow Sydney: Lothian

Gleitzman, Morris 2002 Boy Overboard London: Puffin Books

Green, Michael and Andre Dao (eds), Angelica Neville, Dana Affleck and Sienna Merope (associate eds) 2017 They Cannot Take the Sky Crows Nest: Allen \& Unwin

Green, Melanie and Timothy Brock 2000 'The role of transportation in the persuasiveness of public narratives' Journal of Personality and Social Psychology 79 (5), $701-721$

Green, Melanie 2004 'Transportation into Narrative Worlds: The Role of Prior Knowledge and Perceived Realism' Discourse Processes 38 (2), 247 - 266

Isaacs, Mark 2014 The Undesirables Richmond: Hardie Grant Books

Keen, Suzanne 2006 'A Theory of Narrative Empathy' Narrative 14 (3), 207 - 236

Maley, William 2016 What is a Refugee Melbourne: Scribe Publications

Markus, Andrew 2016 Mapping Social Cohesion: The Scanlon Foundation surveys 2016 November, at http://scanlonfoundation.org.au/wpcontent/uploads/2016/11/2016-Mapping-Social-Cohesion-Report-FINALwith-covers.pdf (accessed 9 February 2017) 
c in d e r

Martin, Greg 2015 'Stop the boats! Moral panic in Australia over asylum seekers' Continuum: Journal of Media and Cultural Studies 29 (3), $304-322$

Strange, Jeffrey and Cynthia Leung 1999 'How anecdotal accounts in news and fiction can influence judgments of a social problem's urgency, causes, and cures' Personality and Social Psychology Bulletin 25 (4), 436 - 449

The Office of the United Nations High Commissioner for Human Rights (OHCHR) 2016 Convention Relating to the Status of Refugees at http://www.ohchr.org/EN/ProfessionalInterest/Pages/StatusOfRefugees.aspx (accessed 26 July 2016)

Wheeler, Christian, Melanie Green and Timothy Brock 1999 'Fictional narratives change beliefs: Replications of Prentice, Gerrig, and Bailis (1997) with mixed corroboration' Psychonomic Bulletin and Review 6 (2), 136 - 141 